\title{
Studying the effect of electrohydraulically treated soil solutions on plant growth and development
}

\author{
Tatyana S. Gridneva*, Sergei V. Mashkov, Vladimir A. Syrkin and Sergei I. Vasilyev
}

Samara State Agrarian University, Samara, 446442, Russia

\begin{abstract}
Increasing agricultural production is an important food task. In providing plants with the necessary nutrients, it is necessary to intensify by applying fertilizers or using alternative environmentally friendly methods. These include technologies that allow the conversion of nutrients into a form accessible to plants, and electrophysical technologies using high-voltage pulse discharge. This article describes the installation for creating electrohydraulic shocks. The experimental studies on the justification of the parameters of electro-hydraulic treatment of solutions and the study of the effect of treatment by solutions treated with electro-hydraulic shock on the development of crops using the example of tomato resulted in obtaining the optimal process technological parameters of the installation. They are voltage $-30 \mathrm{kV}$, discharge capacitance of the capacitor $-0.6 \mu \mathrm{F}$, number of pulses -200 .
\end{abstract}

\section{Introduction}

To increase agricultural production, it is important to provide plants with all the necessary nutrients for growth and development. However, the soil contains a large amount of substances inaccessible for assimilation by plants.

Currently, various technologies are being developed in the world that make it possible to convert nutrients into a form accessible to plants. In most cases they allow excluding additional fertilizing of the soil. Such technologies include electrophysical technologies, for example, using high-voltage pulse discharge. The advantages of such technologies include high efficiency of processes and environmental friendliness. [1-3]

One of the fields of application of the electrohydraulic effect is agriculture.

The authors [4] investigated the possibility of using electric discharge for homogenizing milk and processing whole curd whey in order to improve production and prevent the deposition of undesirable protein sediment.

The technology using electrohydraulic shock allows you to obtain fertilizers from a soil solution (suspension), converting the nutrients contained in it into compounds that are easily assimilated by plants. In natural conditions, this takes years, and with electrohydraulic action occurs almost instantly.

The research carried out by the authors [5] consisted in the treatment of soil suspension, as well as humus solution by electrohydraulic shock. It is concluded that the use of electrohydroimpulse shock allows activating soil processes that contribute to the transition of soil minerals from insoluble forms to easily soluble and easily available for assimilation by plants, starting from the initial stages of their development, which leads to an increase in the efficiency of plant growth.

Thus, the application of the electrohydraulic effect in agriculture is effective and can be widely used for a number of technological operations.

\section{Materials and methods}

"Electrohydraulic shock" is a phenomenon of a highvoltage pulse discharge in a liquid. The impact of electro-hydraulic shock in the soil or peat solution causes the so-called "bacterial explosion", in which there is a significant increase in the number of bacteria that bind atmospheric nitrogen and decompose non-mineralized nitrogen of peat or soil. At the same time, soil processes are activated that contribute to the transition of soil minerals from insoluble forms to readily soluble and readily available for assimilation by plants. [4-6]

To create electrohydraulic shocks, a device was used that includes a power source - a high-voltage transformer 1 (Figure 1), a rectifier 2, a capacitor 3, an air gap 4 , a working clearance formed by electrodes negative 6 and positive 7 (Figure 2), which are placed in a container with a solution 5 .

The active surface of the positive electrode should be much smaller than the negative - this is one of the conditions for obtaining discharges that give the desired effect. The positive and negative electrodes are structurally made of a metal rod with an insulator, the material of which must be a dielectric.

The device can be used in various technological modes - from periodic to continuous, depending on the conditions of the irrigation process.

* Corresponding author: t-grid@mail.ru 

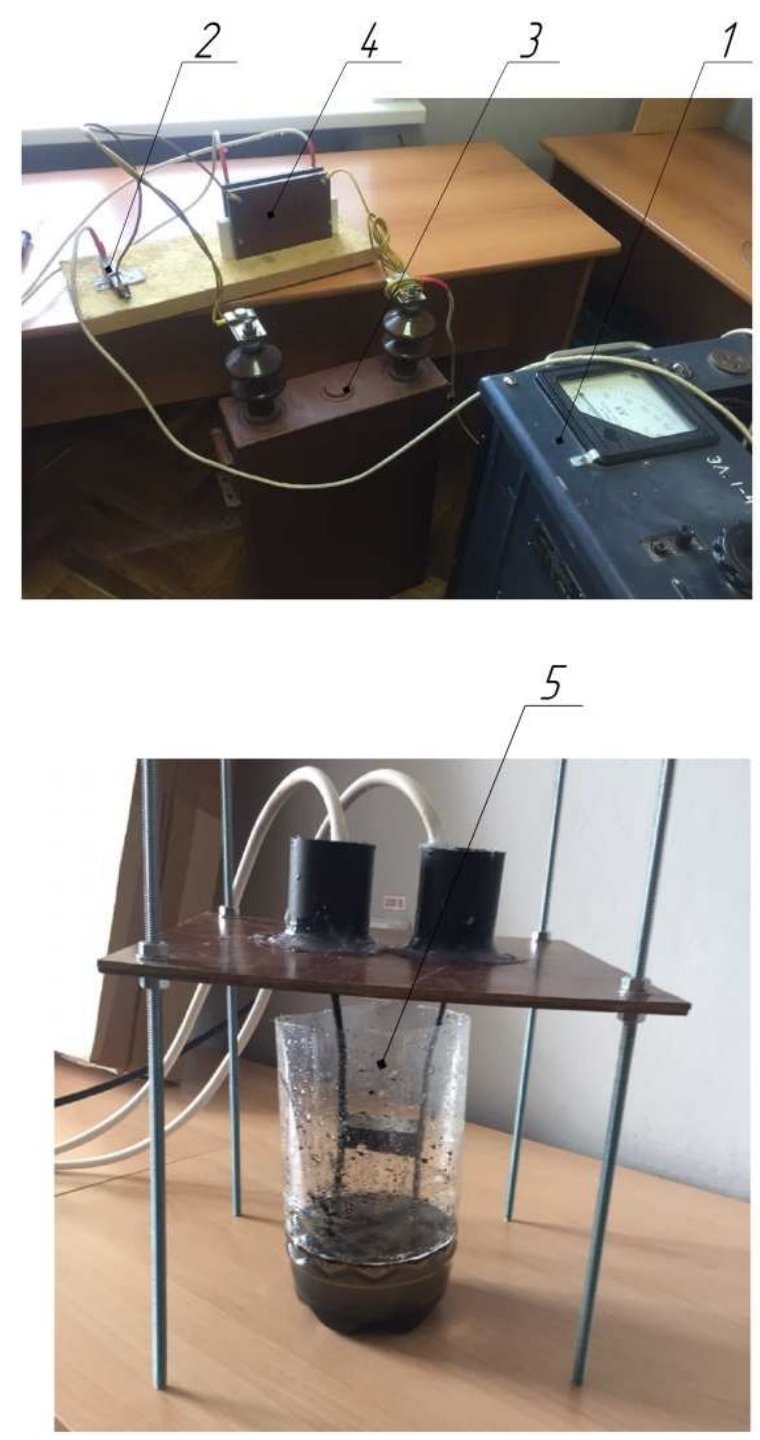

Fig. 1. Diagram of a laboratory installation for electrohydraulic shock: 1 - high-voltage transformer; 2 - rectifier; 3 - capacitor; 4 - air forming gap; 5 - container with a solution

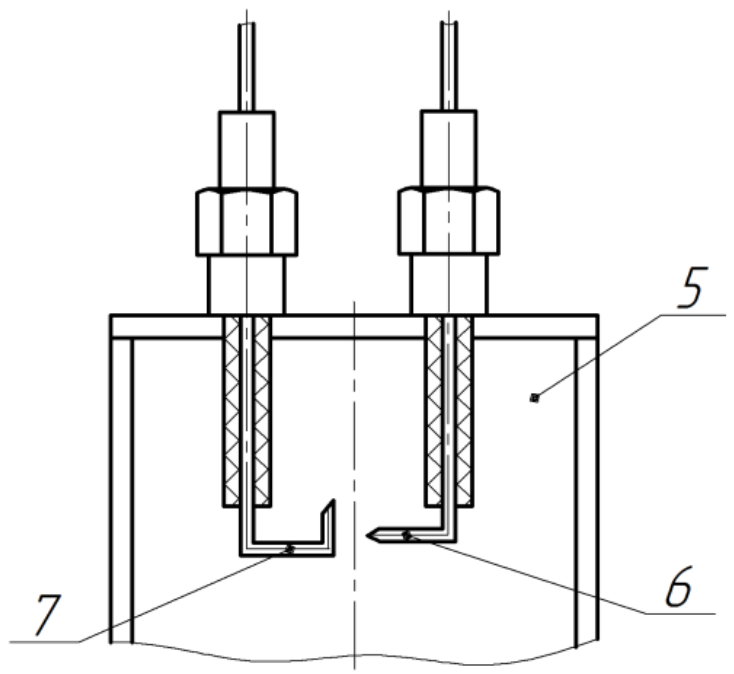

Fig. 2. Diagram of a working clearance: 5 - negative electrode; 6 - positive electrode; 7 - container with a solution
The voltage on the capacitor increases to the value at which the breakdown of the air gap occurs, and all the energy stored in the capacitor enters the working clearance, where it is released as an electric pulse of high power. To achieve the specified processing result, a certain number of pulses is set. The pulse repetition frequency depends on the capacitance value of the capacitor, the applied voltage, and the size of the adjustable forming air gap. [7-10]

The electrical circuit diagram of the installation is shown in Figure 3.

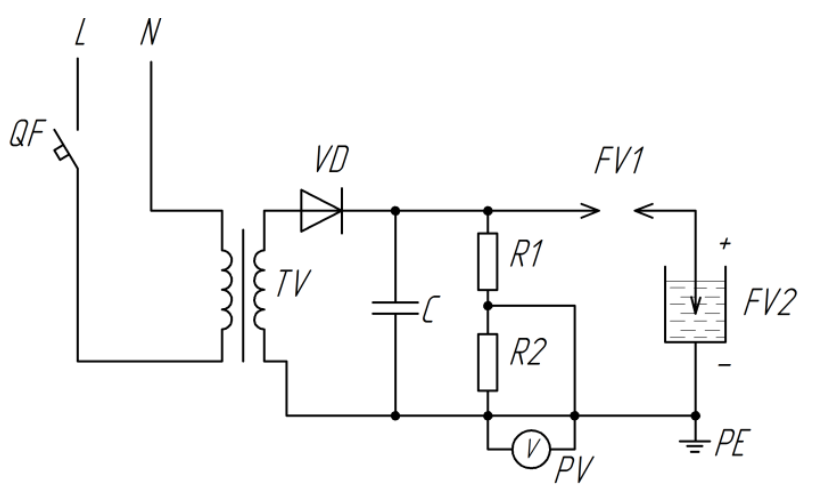

Fig. 3. The circuit diagram: $Q F$ - circuit breaker; $T V$ - a single-phase step-up transformer; $V D$ - rectifying diode; $C$ high-voltage capacitor; $R 1, R 2$ - resistors; $F V 1$ - forming air gap; $F V 2$ - spark working clearance; $P E$ - grounding device

Power is supplied to the circuit using the $Q F$ circuit breaker, which acts as a protective and starting device.

The installation for receiving electro-hydraulic shocks includes $T V$ - a single-phase step-up transformer for converting electrical energy. The transformer has two windings of low $220 \mathrm{~V}$ and high voltage $50 \mathrm{kV} ; \mathrm{VD}-$ rectifying diode for converting alternating current to direct current; $C$ - high-voltage capacitor, stores energy that is released on the spark gap; $R 1, R 2$ - resistors, are used to lower the voltage for connecting a voltmeter; $P V$ - voltmeter; $F V 1$ - forming air gap; $F V 2$ - spark working clearance [6].

Experimental studies were conducted to justify the parameters of electro-hydraulic treatment of solutions.

Five main modes of operation of the electrohydraulic installation were considered: $1-3$ th - at a voltage of $U=10 \mathrm{kV}$ and a capacitance of $C=1.83 ; 3.66$ and $5.49 \mu \mathrm{F}$, respectively, 4th - at $U=20 \mathrm{kV} ; C=0.9 \mu \mathrm{F}$ and the 5 th at $U=30 \mathrm{kV} ; C=0.6 \mu \mathrm{F}$. The modes were provided by series or parallel connection of capacitors with a capacitance of $C=1.83 \mu \mathrm{F}$ and a rated voltage of $10.5 \mathrm{kV}$.

The soil suspension tucked into the working volume was treated with high-voltage pulses in each of the five modes, and the number of pulses in each mode was 100 , 200, and 300 discharges.

The calculated value of the energy spent on processing the liquid in various modes was determined by the formula

$$
W=\frac{C U^{2}}{2}
$$

where $C$ is the capacitance of the capacitor, F;

$U$ is the voltage, $\mathrm{V}$. 
The resulting values are shown in the table 1 .

For each treatment mode and for each number of discharges, a $20 \mathrm{ml}$ sample was taken from the working tank before and after treatment. Measurement of nitrogen content in the soil solution after treatment, with further conversion to $\mathrm{kg}$ of dry soil, was performed using a $\mathrm{pH}$ meter/ionomer, the operating range of which meets the conditions of the experiment and is included in the state register. The $\mathrm{pH}$ meter/iometer is designed for measuring the hydrogen index $(\mathrm{pH})$, redox potential, ion concentration in potable, natural, waste water, water solutions of soil samples, food, food raw materials by potentiometry.

Table 1. The value of the energy invested in the treatment of the liquid at different modes, $\mathrm{kJ}$

\begin{tabular}{|c|c|c|c|c|c|}
\hline 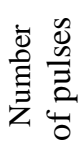 & 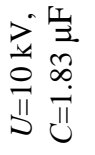 & 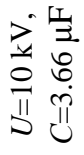 & 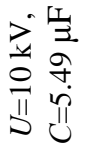 & 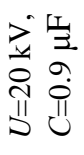 & 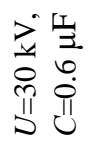 \\
\hline 1 & 0.091 & 0.183 & 0.275 & 0.180 & 0.270 \\
\hline 100 & 9.1 & 18.3 & 27.5 & 18.0 & 27.0 \\
\hline 200 & 18.2 & 36.6 & 55.0 & 36.0 & 54.0 \\
\hline 300 & 27.3 & 54.9 & $82 ., 5$ & 54.0 & 81.0 \\
\hline
\end{tabular}

The second stage of the experiments was to study the effect of pre-sowing treatment of seeds with soil suspension on their further growth and development and consisted in the germination of tomato seeds.

Five experimental groups were made for each plant species, 25 seeds were selected for each of them. The temperature of the experiment was $22{ }^{\circ} \mathrm{C}$, which corresponds to the optimum for seed germination $\left(20 \ldots 25^{\circ} \mathrm{C}\right)$.

The control was represented by the first group, in which the seeds for germination were moistened with distilled water; the second group - untreated soil water suspension; the third group is a soil water suspension treated with electro-hydraulic shock.

\section{Results}

The results of experiments with different modes of fluid treatment are presented in the Table 2 and Figure 4. In the process of electrohydraulic treatment of the soil solution, the mass content of nutrients and microelements in it changes sharply compared to the original, upward.

The results show that the mass content of ammonia nitrogen increases 2.7-3.8 times. When storing a soil solution that has undergone electrohydraulic shock treatment, on the 10-15th day of storage it leads to a sharp (9-10 times) increase in the mass content of soluble nitrogen compounds in it due to the "bacterial explosion". This process, after processing, continues for a certain time, after which the state stabilizes.

Thus, the 5th mode of operation of the electrohydraulic installation $(U=30 \mathrm{kV} ; C=0.6 \mu \mathrm{F})$, which corresponds to a high discharge voltage and a relatively small capacitance of the capacitor, provides the greatest bactericidal effect. The optimal number of pulses for processing a portion of the solution is 200 pcs. A larger number of pulses does not lead to an increase in the nitrogen content, and the energy expended in this case increases.

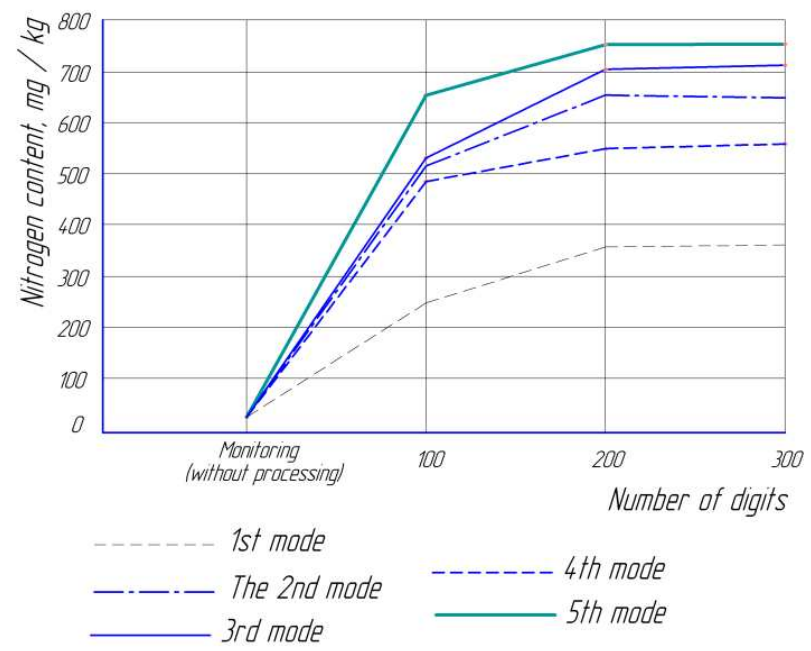

Fig. 4. The dependence of the nitrogen content in the soil solution after treatment on the treatment regimes

The results of laboratory studies of the effect of electrohydraulic treatment of soil solutions on the growth and development of tomato showed that the best germination results were achieved by soaking the seeds and watering the samples with a soil extract treated with electro-hydraulic shock (option No. 3).

Seedlings of seeds was observed on the second or third day, which corresponded to the data of pre-sowing soaking under optimal conditions. When the seeds were wetted with distilled water (control), about half of the seeds hatch on the sixth day, on the seventh day all sprouted, in some of the seeds the germinal roots were clearly visible. In group 2, all seeds nested on the sixth day, but on the seventh day there was no significant increase in the length of germinal roots. In group 3, the third part of the seeds hatched on the sixth day, and on the next day all the seeds had germinated, and at the same time, the germinal roots of all had reached considerable size.

The supply of nutrients in the seeds was approximately the same, so a significant increase in germinal roots in group 3 can be explained by the fact that nutrients were used not only from internal reserves (endosperm), but also from a soil suspension with readily available elements of plant mineral nutrition (after treatment with electrohydraulic shock). [4]

Similar results were recorded when observing the growth of tomato germs (seedlings). Observations of the length of tomato seedlings were carried out before the start of growth and showed that from the moment of emergence of seedlings (on the 6th day) and until the end of the observation (10th day), the length of seedlings in option No. 3 was almost twofold in comparison with options No. 1 (control) and No. 2 (treatment and irrigation of untreated soil suspension) (Figure 5). 
Table 2. Nitrogen content in the soil solution after treatment

\begin{tabular}{|c|c|c|c|c|c|}
\hline \multirow[t]{3}{*}{ Mode } & \multirow{3}{*}{$\begin{array}{l}\text { Number of } \\
\text { discharges }\end{array}$} & \multicolumn{4}{|c|}{$\begin{array}{l}\mathrm{NH} 4 \text { (nitrogen) content per } \mathrm{kg} \text { of } \\
\text { dry soil, } \mathrm{mg} / \mathrm{kg}\end{array}$} \\
\hline & & \multirow{2}{*}{\begin{tabular}{|c} 
Before \\
processing \\
(control)
\end{tabular}} & \multicolumn{3}{|c|}{ After processing } \\
\hline & & & \begin{tabular}{|l|} 
After \\
3 days \\
\end{tabular} & $\begin{array}{l}\text { After } \\
14 \text { days }\end{array}$ & $\begin{array}{c}\text { After } \\
28 \text { days }\end{array}$ \\
\hline \multirow{3}{*}{$\begin{array}{c}1 \text { st }(U=10 \mathrm{kV}, \\
C=1.83 \mu \mathrm{F})\end{array}$} & 100 & \multirow{15}{*}{19.6} & 34.5 & 233.6 & 210.6 \\
\hline & 200 & & 40.2 & 360.5 & 360.9 \\
\hline & 300 & & 42.6 & 369.2 & 370.0 \\
\hline \multirow{3}{*}{$\begin{array}{c}2 \mathrm{nd}(U=10 \mathrm{kV} \\
C=3.66 \mu \mathrm{F})\end{array}$} & 100 & & 51.2 & 522.6 & 526.5 \\
\hline & 200 & & 60.2 & 656.8 & 656.9 \\
\hline & 300 & & 61.5 & 652.2 & 658.0 \\
\hline \multirow{3}{*}{$\begin{array}{c}3 \mathrm{rd}(U=10 \mathrm{kV}, \\
C=5.49 \mu \mathrm{F})\end{array}$} & 100 & & 54.2 & 532.1 & 525.0 \\
\hline & 200 & & 69.7 & 705.5 & 708.8 \\
\hline & 300 & & 70.3 & 713.0 & 699.5 \\
\hline \multirow{3}{*}{$\begin{array}{c}\text { 4th }(U=20 \mathrm{kV} \\
C=0.9 \mu \mathrm{F})\end{array}$} & 100 & & 48.4 & 490.5 & 495.8 \\
\hline & 200 & & 55.4 & 562.3 & 553.1 \\
\hline & 300 & & 56.6 & 552.0 & 560.0 \\
\hline \multirow{3}{*}{$\begin{array}{c}\text { 5th }(U=30 \mathrm{kV} \\
C=0.6 \mu \mathrm{F})\end{array}$} & 100 & & 69.5 & 660.0 & 635.8 \\
\hline & 200 & & 73.6 & 759.0 & 755.0 \\
\hline & 300 & & 75.5 & 759.5 & 750.5 \\
\hline
\end{tabular}

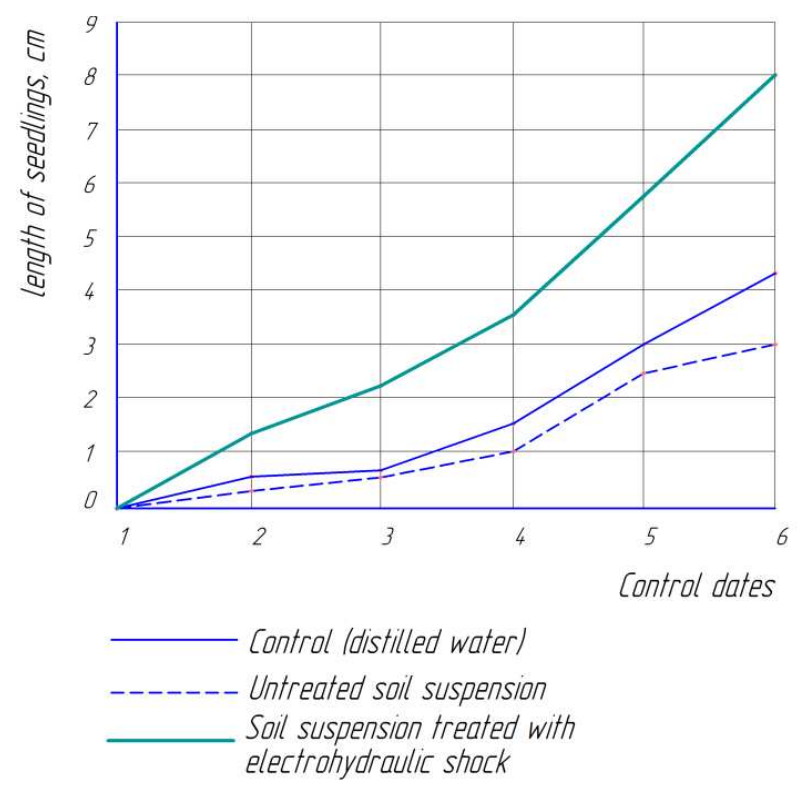

Fig. 5. Change in the length of seedlings of tomato seeds by days (from the moment of seed swelling, planting 03/10/2020). Dates of control: 1 - 15/3/20; 2 - 16/3/20; $3-17 / 3 / 20 ; 4-18 / 3 / 20 ; 5-19 / 3 / 20 ; 6-20 / 3 / 20$

\section{Conclusion}

The technology for pre-sowing seed treatment was improved by applying a soil solution that had undergone electro-hydraulic shock treatment to soak the seeds before sowing.

The soil solution is prepared at the rate of $600 \mathrm{~g}$ of soil per 31 of distilled water. The processing energy was $81 \mathrm{~kJ}$. To implement the technology, an installation was developed for electrohydraulic processing of solutions, containing a cylindrical tank, upper and lower covers, inlet and outlet nozzles for supplying and removing the treated liquid, and positive and negative electrodes. The positive electrode is made of a rod, the negative electrode is made of a longer rod.

Thus, we can conclude that the use of electrohydraulic shock will increase the nutritional value of soil solutions, transforming nutrients into a form accessible to plants. The optimum technological parameters of the installation for electro-hydraulic treatment of solutions were experimentally substantiated, which were: voltage $-30 \mathrm{kV}$, discharge capacitance of the capacitor $-0.6 \mu \mathrm{F}$, number of pulses -200 .

\section{References}

1. S.S. Nugmanov, S.I. Vasiliev, T.S. Gridneva et al., Improvement of electrophysical methods and technical means for influencing agricultural objects, Monograph (2019)

2. A.A. Bekaev, A.R. Abramov, I.A. Tsvetkov, Using the L.A. Yutkin effect in electrohydraulic devices, Tract. and agricult. Mach. 12, 10-12 (2010)

3. S.I. Vasilev, S.V. Mashkov, V.A. Syrkin et al., Results of studies of plant stimulation in a magnetic field, Res. J. of Pharmac., Biolog. and Chem. Sci. 4, 706-710 (2018)

4. A.V. Kochubey-Lytvynenko, O.A. Cernosek, V.V. Olishevsky et al., The effect of electro-treatment on the dispersibility of cheese whey, Dairy industry $\mathbf{8}$, 31-33 (2014)

5. N.A. Sokolova, V.V. Gamaga, S.E. Grachev et al., Study of the influence of electrohydraulic treatment of soil solutions on plant growth and development, Bull. of the Stavropol agro-industr. complex 2, 68-72 (2015)

6. V.N. Toporkov, Electric Pulse technologies in agriculture, Bull. of agrar. sci. of the Don 2, 50-55 (2019)

7. B.R. Locke, M. Sato, P. Sunka, M.R. Hoffmann, J.-S. Chang, Electrohydraulic discharge and nonthermal plasma for water treatment, Industrial and Engineering Chemistry Research, Amer. Chem. Society 3, 882-905 (2006)

8. A.A. Belov, A.A., Musienko, A.N. Vasiliev, V.N. Toporkov, Justification of the device for electrohydraulic treatment of water solutions, Bull. of agrar. Sci. of the Don 2, 23-29 (2019)

9. D.C. Bian, D. Yan, J.C. Zhao, S.Q. Niu, Experimental Study of Pulsed Discharge Underwater Shock-Related Properties in Pressurized Liquid Water, Advan. in Mater. Sci. and Engineer. Art. 8025708 (2018)

10. N.K.V. Leitner, G. Syoen, H. Romat, K. Urashima, J.S. Chang, Generation of active entities by the pulsed arc electrohydraulic discharge system and application to removal of atrazine, Water Res. 19, 4705-4714 (2005)

11. J.W. Mackersie, I.V. Timoshkin, S.J. MacGregor, Generation of high-power ultrasound by spark discharges in water, IEEE Transact. on Plasma Sci. 33, 1715-1724 (2005) 